\title{
Establishing a prognostic model for metachronous second squamous cell lung cancer in patients with resected squamous cell lung cancer
}

\author{
Shen-Shen Fu ${ }^{1 \#}$, Yu-Zhen Zheng ${ }^{2 \#}$, Xian-Yu Qin ${ }^{2}$, Xing-Ping Yang ${ }^{2}$, Piao Shen ${ }^{3}$, Wei-Jie Cai ${ }^{2}$, Xiao-Qiang Li $^{4}$, \\ Hong-Ying Liao ${ }^{2}$ \\ ${ }^{1}$ Department of Ultrasonography, Guangzhou First People's Hospital, The Second Affiliated Hospital of South China University of Technology, \\ Guangzhou, China; ${ }^{2}$ Department of Thoracic Surgery, The Sixth Affiliated Hospital, Sun Yat-sen University, Guangzhou, China; ${ }^{3}$ Department of \\ Thoracic Surgery, Affiliated Cancer Hospital \& Institute of Guangzhou Medical University, Guangzhou, China; ${ }^{4}$ Department of Thoracic Surgery, \\ Peking University Shenzhen Hospital, Shenzhen, China \\ Contributions: (I) Conception and design: SS Fu, YZ Zheng, XQ Li, HY Liao; (II) Administrative support: SS Fu, YZ Zheng, XQ Li, HY Liao; \\ (III) Provision of study materials or patients: XY Qin, XP Yang; (IV) Collection and assembly of data: P Shen, WJ Cai; (V) Data analysis and \\ interpretation: SS Fu, YZ Zheng; (VI) Manuscript writing: All authors; (VII) Final approval of manuscript: All authors. \\ \#These authors contributed equally to this work. \\ Correspondence to: Professor Xiao-Qiang Li, MD. Department of Thoracic Surgery, Peking University Shenzhen Hospital, Shenzhen 518036, China. \\ Email: dr.lixiaoqiang@gmail.com; Professor Hong-Ying Liao, MD. Department of Thoracic Surgery, The Sixth Affiliated Hospital, Sun Yat-sen \\ University, Guangzhou, China. Email: liaohy2@mail.sysu.edu.cn.
}

Background: For metachronous second pulmonary squamous cell carcinoma (msPS) in patients with resected PSC, the method to distinguish tumour clonality has not yet been well established, which makes it difficult to determine accurate staging and predict prognosis.

Methods: Patients who underwent surgery for first PSC and encountered msPSC were recruited from the Surveillance, Epidemiology, and End Results (SEER) database. We extracted overall survival 1 (OS1) for the first PSC, overall survival 2 (OS2) for msPSC, and interval survival for the time interval between the first and second PSC. The nomogram was calibrated for OS2, and recursive partitioning analysis (RPA) was performed for risk stratification.

Results: A total of 617 patients were identified. Several independent prognostic factors were identified and integrated into the nomogram for OS2, including gender, age $\left(2^{\text {nd }}\right)$, nodal status $\left(1^{\text {st }}\right)$, node metastasis $\left(2^{\text {nd }}\right)$, and extrapulmonary metastasis $\left(2^{\text {nd }}\right)$. The calibration curves showed optimal agreement between the predictions and actual observations, and the c-index was 0.678. Surgery was associated with longer survival for msPSC patients. The prognosis of sublobectomy was comparable and inferior to that of lobectomy in the low- and moderate-risk groups, respectively. Radiotherapy was associated with better outcomes in patients who did not undergo surgery.

Conclusions: The RPA-based clinical nomogram appears to be suitable for the prognostic prediction and risk stratification of OS2 in msPSC. This practical system may help clinicians make decisions and design clinical studies.

Keywords: Metachronous lung cancer; squamous cell carcinoma (SCC); prognostic model

Submitted Jul 13, 2021. Accepted for publication Dec 02, 2021.

doi: $10.21037 /$ jtd-21-1164

View this article at: https://dx.doi.org/10.21037/jtd-21-1164

(c) Journal of Thoracic Disease. All rights reserved. 


\section{Introduction}

Non-small cell lung cancer (NSCLC) is one of the most common malignancies, causing 1,761,007 deaths worldwide in 2018 (1). Squamous cell carcinoma (SCC) represents approximately $30 \%$ of NSCLC cases (2). During the past decades, great advances have been made in surgery, cytotoxic drugs, radiotherapy, targeted therapy, and immunotherapy for NSCLC, the prognosis has been greatly improved, and the number of survivors has increased (3). Because the reported risk of developing metachronous second primary lung cancer varies from $1 \%$ to $7 \%$ per survivor per year, the number of second lung cancers is expected to rapidly increase (4-6). The physical conditions of patients with second lung cancer are commonly limited, which makes the clinical decision more cautious and complex. In addition, when the pathological type of metachronous second lung cancer is the same as the first, it is hard to determine its origin (primary or metastatic lung cancer). Accurate stage information and appropriate treatment decisions would be difficult to determine in this situation. Assessments of several clinical parameters, including the location of the primary tumour and metastatic node, tumour diameter, histology, and cancer-free survival, have long been used to distinguish multiple primary lung cancer (MPLC) from metastasis (7-10). However, these suggestions remain controversial owing to contradictory results reported by series studies (11-13). Establishing a prognostic model for metachronous second lung cancer presenting the same pathology as first lung cancer would be greatly helpful for prognostic prediction and treatment decision making.

In this study, we used the population-based Surveillance, Epidemiology, and End Results (SEER) registry to include patients with resected pulmonary squamous cell carcinoma (PSC) and further encountered metachronous second pulmonary squamous cell carcinoma (msPSC). The aim of this study was to build a prognostic model and risk stratification system for these msPSCs and explore its effectiveness in assisting treatment decisions.

We present the following article in accordance with the STROBE reporting checklist (available at https://jtd. amegroups.com/article/view/10.21037/jtd-21-1164/rc).

\section{Methods}

\section{Study population}

The study was conducted in accordance with the
Declaration of Helsinki (as revised in 2013). The study was approved by institutional ethics board of Guangzhou First People's Hospital (K-2020-066-01) and individual consent for this retrospective analysis was waived. The population was selected from the SEER 18 Custom Database using SEER*Stat 8.3.5 software (http://seer.cancer.gov/seerstat/).

Patients from the SEER 18 Regs excluding the AK Custom database (2000 to 2015) with additional treatment fields who had pathologically confirmed lung cancer with squamous cell pathology (International Classification of Diseases for Oncology, Third edition: 8070-8078) as their first malignant tumour and suffered metachronous NSCLC in their patient history were screened. In this cohort, we identified patients according to the following criteria: (I) underwent surgical resection (lobectomy, sublobectomy, or pneumonectomy) for the first PSC; and (II) the pathology for metachronous NSCLC was squamous cell pathology (International Classification of Diseases for Oncology, Third edition: 8070-8078). msPSC was defined as the second lung squamous cell cancer which occurred after diagnosis of the first lung cancer, therefore patients with interval survival $\leq 1$ month were excluded in this study.

The patients' sociodemographic information and clinicopathological parameters for the first PSC and msPSC were collected. For the first PSC, staging was manually performed according to the 8th TNM staging system. Because the tumour characteristics (primary or metastatic cancer) of msPSCs are unclear, the pathological parameters of msPSCs were recorded in an altered way, including tumour diameter ( $<20 \mathrm{~mm}, 20-49 \mathrm{~mm}, \geq 50 \mathrm{~mm}$ ), node metastasis (negative, positive), and extrapulmonary metastasis (no, yes). Two recorded variables, "site-specific surgery codes" and "surgery of primary site codes", were adopted to identify the surgical procedure.

\section{Statistical analysis}

The statistical analysis was performed using the SPSS 22.0 software package (SPSS, Inc., Chicago, IL, USA). The survival rate was calculated using the Kaplan-Meier method, and the differences between curves were assessed by the log-rank test. Due to the rules of submitted survival data in the SEER database, overall survival (OS) was adopted as the survival outcome in this study. The survival data of the first PSC were extracted and defined as overall survival 1 (OS1), which means the time duration between surgery date of first PSC and last follow-up or death; and the survival data of msPSC were extracted and defined as 


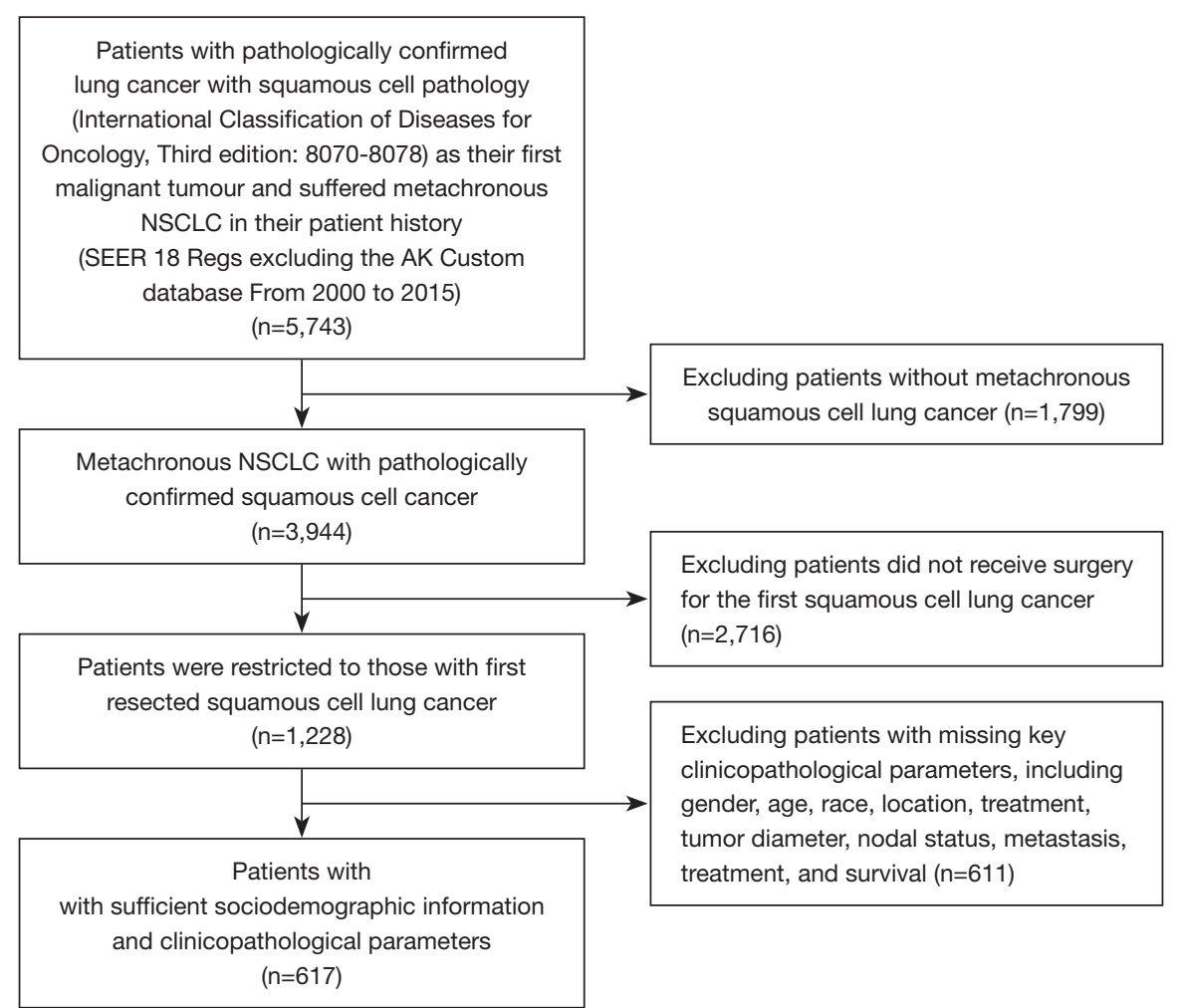

Figure 1 Definition of overall survival 1, overall survival 2, and interval survival for patients with metachronous second squamous cell lung cancer. NSCLC, non-small cell lung cancer; SEER, Surveillance, Epidemiology, and End Results.

overall survival 2 (OS2), which means the time duration between treatment date of msPSC and last follow-up or death. Interval survival is defined as OS1 minus OS2, which indicated as the time duration between surgery date of first PSC and treatment date of msPSC (Figure 1). In this study, the main objective is OS2.

Univariate Cox regression models were constructed to identify predictors for interval survival, OS1, and OS2. Categorical clinicopathological parameters were included in the univariate Cox analysis, including gender, race, age $\left(1^{\text {st }}\right)$, location $\left(1^{\text {st }}\right)$, grade $\left(1^{\text {st }}\right)$, surgery $\left(1^{\text {st }}\right)$, radiotherapy $\left(1^{\text {st }}\right)$, chemotherapy $\left(1^{\text {st }}\right)$, tumour diameter $\left(1^{\text {st }}\right)$, nodal status $\left(1^{\text {st }}\right)$, distant metastasis $\left(1^{\text {st }}\right)$, age $\left(2^{\text {nd }}\right)$, location $\left(2^{\text {nd }}\right)$, side of second PSC, grade $\left(2^{\text {nd }}\right)$, tumour diameter $\left(2^{\text {nd }}\right)$, node metastasis $\left(2^{\text {nd }}\right)$, and extrapulmonary metastasis $\left(2^{\text {nd }}\right)$. For the evaluation of OS1 and OS2, the interval survival parameter was also included in the univariate analysis. According to the criteria for the diagnosis of MSPLC proposed by the American College of Chest Physicians (ACCP) in 2013, 24 and 48 months were selected as the cut-off points for interval survival (7). Factors shown with potential significance $(\mathrm{P}<0.1)$ in univariate analysis were introduced into multivariate Cox regression analysis. Considering the natural impact of tumor diameter $\left(1^{\text {st }}\right)$, node metastasis $\left(1^{\text {st }}\right)$, and surgery $\left(1^{\text {st }}\right)$ on OS1, these parameters would be introduced into multivariate analysis even through the $\mathrm{P}$ value is larger than 0.1 . Statistical significance was assumed at a two-sided $\mathrm{P}<0.05$.

To establish a prognostic prediction system for OS2, a nomogram was formulated with the survival and rms packages on the basis of multivariate analysis (14). The nomogram was subjected to 1,000 bootstrap resamples for internal validation of the primary cohort. Calibration of the nomogram for 3- and 5-year OS was performed by comparing the predicted survival with the observed survival after bias correction. The Akaike information criterion (AIC) as well as the concordance index (c-index) were applied to the Cox proportional hazards regression model to correct for potential bias in comparing prognostic systems with different numbers of stages. A new decision tree group was established for the risk stratification of OS2 through recursive partitioning analysis (RPA). This 
method modelled predictors by building decision trees. In every node, each predictor was examined for the best split within that variable and the optimal split corresponding to which has the greatest survival difference between patient groups (15). The efficacy of surgery, chemotherapy, and radiotherapy was evaluated according to the risk stratification system. In this research, the nomogram score was the only predictor, and the PRA was performed using $\mathrm{R}$ 3.3.2 (http://www.r-project.org) with the part package. All parameters were set to default values.

\section{Results}

\section{Patient characteristics}

A total of 617 patients who met the criteria were included in this study (Table 1). The median ages for first PSC and msPSC were 69 (range, from 30 to 86) and 73 (range, 31 to 91) years, respectively. The median tumour diameters for the first PSC and msPSC were 30 (range, 4 to 95) and 20 (range, 5 to 96 ) $\mathrm{mm}$, respectively. The median interval survival was 48 (range, from 2 to 141) months. There were

Table 1 Patient characteristics

\begin{tabular}{lc}
\hline Variable & Case number \\
\hline Gender & $378(61.3)$ \\
Male & $239(38.7)$ \\
Female & \\
Race & $552(89.5)$ \\
White & $48(7.8)$ \\
Black & $17(2.8)$ \\
Others & \\
Age (1 ${ }^{\text {st }}$ (years) & $352(57.1)$ \\
$<70$ & $265(42.9)$ \\
$\geq 70$ & \\
Location (1 $1^{\text {st }}$ & $196(31.8)$ \\
Left upper & $108(17.5)$ \\
Left lower & $172(27.9)$ \\
Right upper & $28(4.5)$ \\
Right middle & $98(15.9)$ \\
Right lower & $15(2.4)$ \\
Unknown &
\end{tabular}

Table 1 (continued)
Table 1 (continued)

\begin{tabular}{|c|c|}
\hline Variable & Case number \\
\hline \multicolumn{2}{|c|}{ Tumor diameter $\left(1^{\mathrm{st}}\right)(\mathrm{mm})$} \\
\hline$<20$ & $139(22.5)$ \\
\hline $20-49$ & $346(56.1)$ \\
\hline$\geq 50$ & $132(21.4)$ \\
\hline \multicolumn{2}{|l|}{ Nodal status $\left(1^{\text {st }}\right)$} \\
\hline No & $519(84.1)$ \\
\hline N1 & $61(9.9)$ \\
\hline N2 & $37(6.0)$ \\
\hline \multicolumn{2}{|l|}{ Grade $\left(1^{\text {st }}\right)$} \\
\hline I & $12(1.9)$ \\
\hline II & $317(51.4)$ \\
\hline III & $261(42.3)$ \\
\hline IV & $5(0.8)$ \\
\hline Unknown & $22(3.6)$ \\
\hline \multicolumn{2}{|c|}{ Distant metastasis $\left(1^{\text {st }}\right)$} \\
\hline Mo & $599(97.1)$ \\
\hline M1 & $18(2.9)$ \\
\hline \multicolumn{2}{|l|}{ Stage $\left(1^{\text {st }}\right)$} \\
\hline I & $470(76.2)$ \\
\hline II & $70(11.4)$ \\
\hline III & $59(9.7)$ \\
\hline IV & $18(2.8)$ \\
\hline \multicolumn{2}{|l|}{ Surgery $\left(1^{\text {st }}\right)$} \\
\hline Sublobectomy & $87(14.1)$ \\
\hline Lobectomy & $506(82.0)$ \\
\hline Pneumonectomy & $24(3.9)$ \\
\hline \multicolumn{2}{|l|}{ Chemotherapy $\left(1^{\text {st }}\right)$} \\
\hline Yes & $126(20.4)$ \\
\hline No/unknown & $491(79.6)$ \\
\hline \multicolumn{2}{|l|}{ Radiotherapy $\left(1^{\text {st }}\right)$} \\
\hline Yes & $59(9.6)$ \\
\hline No/unknown & $558(90.4)$ \\
\hline \multicolumn{2}{|c|}{ Interval survival (months) } \\
\hline$<24$ & $168(27.2)$ \\
\hline $24-47$ & $201(32.6)$ \\
\hline$\geq 48$ & $248(40.2)$ \\
\hline
\end{tabular}

Table 1 (continued) 
Table 1 (continued)

\begin{tabular}{|c|c|}
\hline Variable & Case number \\
\hline \multicolumn{2}{|l|}{ Age $\left(2^{\text {nd }}\right)$ (years) } \\
\hline$<70$ & $214(34.7)$ \\
\hline$\geq 70$ & 403 (65.3) \\
\hline \multicolumn{2}{|l|}{ Location $\left(2^{\text {nd }}\right)$} \\
\hline Left upper & $165(26.7)$ \\
\hline Left lower & $105(17.0)$ \\
\hline Right upper & 160 (25.9) \\
\hline Right middle & $24(3.9)$ \\
\hline Right lower & $127(20.6)$ \\
\hline Unknown & $36(5.8)$ \\
\hline \multicolumn{2}{|c|}{ Tumor diameter $\left(2^{\text {nd }}\right)(\mathrm{mm})$} \\
\hline$<20$ & $244(39.5)$ \\
\hline $20-49$ & $227(36.8)$ \\
\hline$\geq 50$ & $146(23.7)$ \\
\hline \multicolumn{2}{|c|}{ Node metastasis $\left(2^{\text {nd }}\right)$} \\
\hline Negative & $469(76.0)$ \\
\hline Positive & $148(24.0)$ \\
\hline \multicolumn{2}{|c|}{ Extrapulmonary metastasis $\left(2^{\text {nd }}\right)$} \\
\hline No & $540(87.5)$ \\
\hline Yes & 77 (12.5) \\
\hline \multicolumn{2}{|l|}{ Grade $\left(2^{\text {nd }}\right)$} \\
\hline I & $10(1.6)$ \\
\hline II & $269(43.6)$ \\
\hline III & $172(27.9)$ \\
\hline IV & $3(0.5)$ \\
\hline Unknown & $163(26.4)$ \\
\hline \multicolumn{2}{|l|}{ Surgery $\left(2^{\text {nd }}\right)$} \\
\hline No surgery & $363(58.8)$ \\
\hline Sublobectomy & $153(24.8)$ \\
\hline Lobectomy & $101(16.4)$ \\
\hline \multicolumn{2}{|c|}{ Chemotherapy $\left(2^{\text {nd }}\right)$} \\
\hline Yes & $140(22.7)$ \\
\hline No/unknown & $477(77.3)$ \\
\hline \multicolumn{2}{|c|}{ Radiotherapy $\left(2^{\text {nd }}\right)$} \\
\hline Yes & $255(41.3)$ \\
\hline No/unknown & $362(58.7)$ \\
\hline
\end{tabular}

$477(77.3 \%)$ msPSCs located on the contralateral side with respect to the first PSC. Surgery was performed in 254 msPSC patients, including 153 sublobectomies and 101 lobectomies. The median survival times for interval survival, OS1, and OS2 were 41, 86, and 28 months, respectively. Flow chart of patient recruitment is shown in Figure 2.

\section{Predictors for interval survival, OS1, and OS2}

After univariate analysis, factors with potential significance were further included in multivariate analysis. As shown in Table 2, for interval survival, the potential predictors were age $\left(1^{\text {st }}\right)$, side of second PSC, chemotherapy $\left(1^{\text {st }}\right)$, and surgery $\left(1^{\text {st }}\right)$, and the factors that maintained significance after multivariate analysis were age $\left(1^{\text {st }}\right)$ (adjusted HR $=1.210, \mathrm{P}=0.020$ ) and side of second PSC (adjusted HR $=1.325, \mathrm{P}=0.004)$. For OS1, the potential predictors were gender, age $\left(1^{\text {st }}\right)$, interval survival, tumor diameter $\left(1^{\text {st }}\right)$, nodal status (2st), and surgery $\left(1^{\text {st }}\right)$, and the factors that maintained significance after multivariate analysis were gender (adjusted HR =0.711, P=0.002), age $\left(1^{\text {st }}\right.$ ) (adjusted $\mathrm{HR}=1.301, \mathrm{P}=0.013)$, interval survival $(\mathrm{P}<0.001)$. For OS2, the potential predictors were gender, age $\left(2^{\text {nd }}\right)$, interval survival, tumour diameter $\left(1^{\text {st }}\right)$, nodal status $\left(1^{\text {st }}\right)$, tumour diameter $\left(2^{\text {nd }}\right)$, node metastasis $\left(2^{\text {nd }}\right)$, and extrapulmonary metastasis $\left(2^{\text {nd }}\right)$, and the factors that maintained significance after multivariate analysis were gender (adjusted HR $=0.750, \mathrm{P}=0.012)$, age $\left(2^{\text {nd }}\right)$ (adjusted $\left.\mathrm{HR}=1.364, \mathrm{P}=0.006\right)$, nodal status $\left(1^{\text {st }}\right)(\mathrm{P}=0.047)$, tumour diameter $\left(2^{\text {nd }}\right)(\mathrm{P}<0.001)$, node metastasis (adjusted HR $=1.313, \mathrm{P}=0.030$ ), and extrapulmonary metastasis (adjusted $\mathrm{HR}=2.219, \mathrm{P}<0.001$ ).

\section{Nomogram and risk stratification for OS2}

A nomogram that incorporated the aforementioned significant prognostic factors was established for OS2 (Figure 3A). The nomogram illustrated that tumour diameter $\left(2^{\text {nd }}\right)$ and extrapulmonary metastasis $\left(2^{\text {nd }}\right)$ had the largest contributions to prognosis. Each subtype within these variables was assigned a score on the point scale (Table S1). By adding up the scores, we could obtain the nomogram score of each patient (median, 78.6; range, 0-287.3). The calibration plots presented good agreement between the nomogram predictions and actual observations for the 3- and 5-year survival rates (Figure 3B). The AIC value was 3208.599, and the c-index was 0.678 (95\% CI: $0.642-0.713)$. These results proved the predictive efficacy of our established nomogram for long-term survival. Then, we 


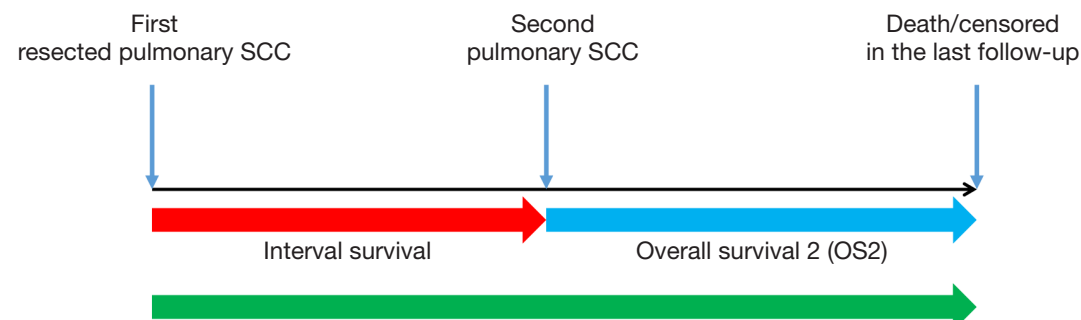

Overall survival 1 (OS1)

Figure 2 Flow chart of patient recruitment.

Table 2 Univariate and multivariate analysis for overall survival 1, interval survival, and overall survival 2.

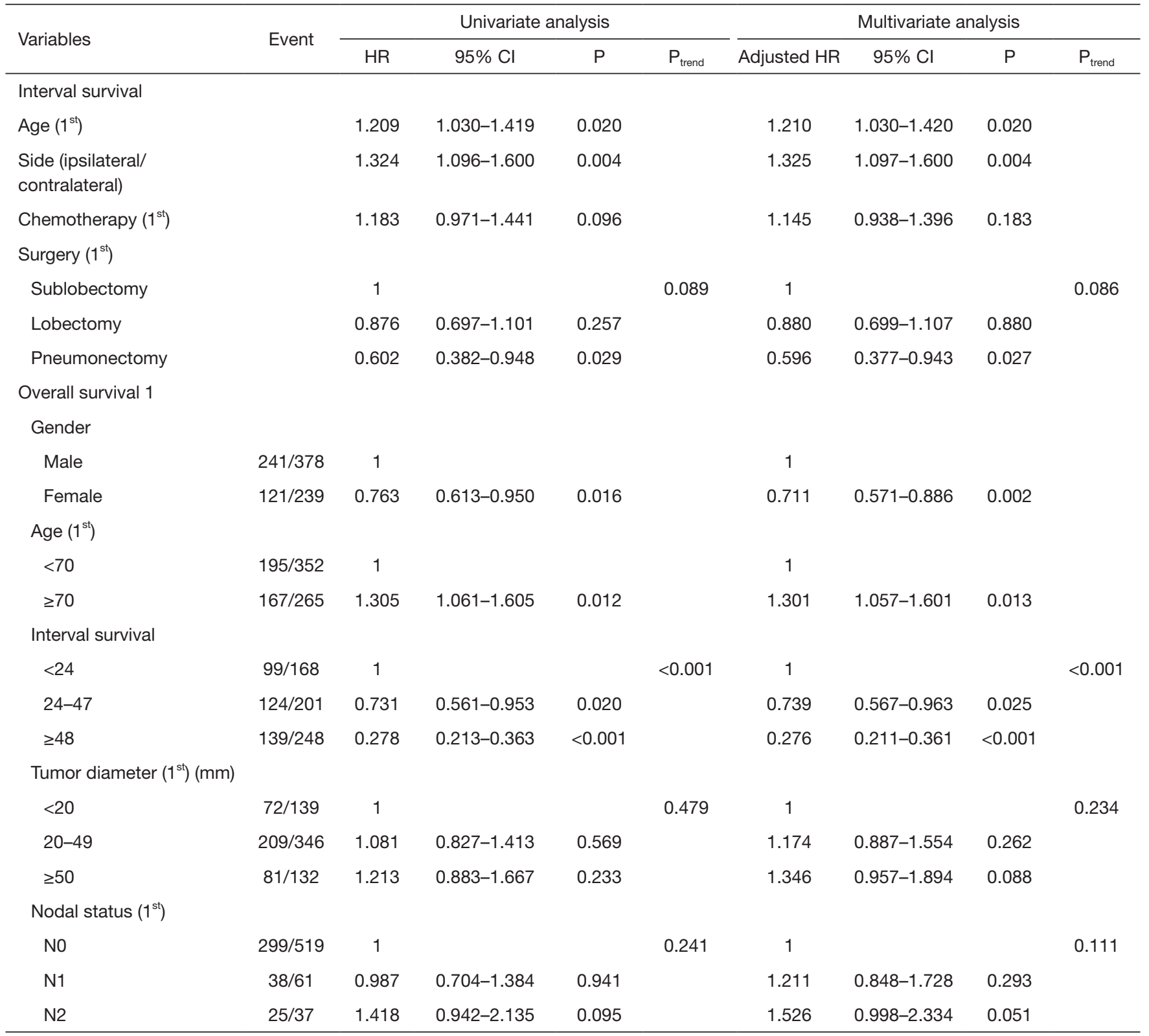

Table 2 (continued) 
Table 2 (continued)

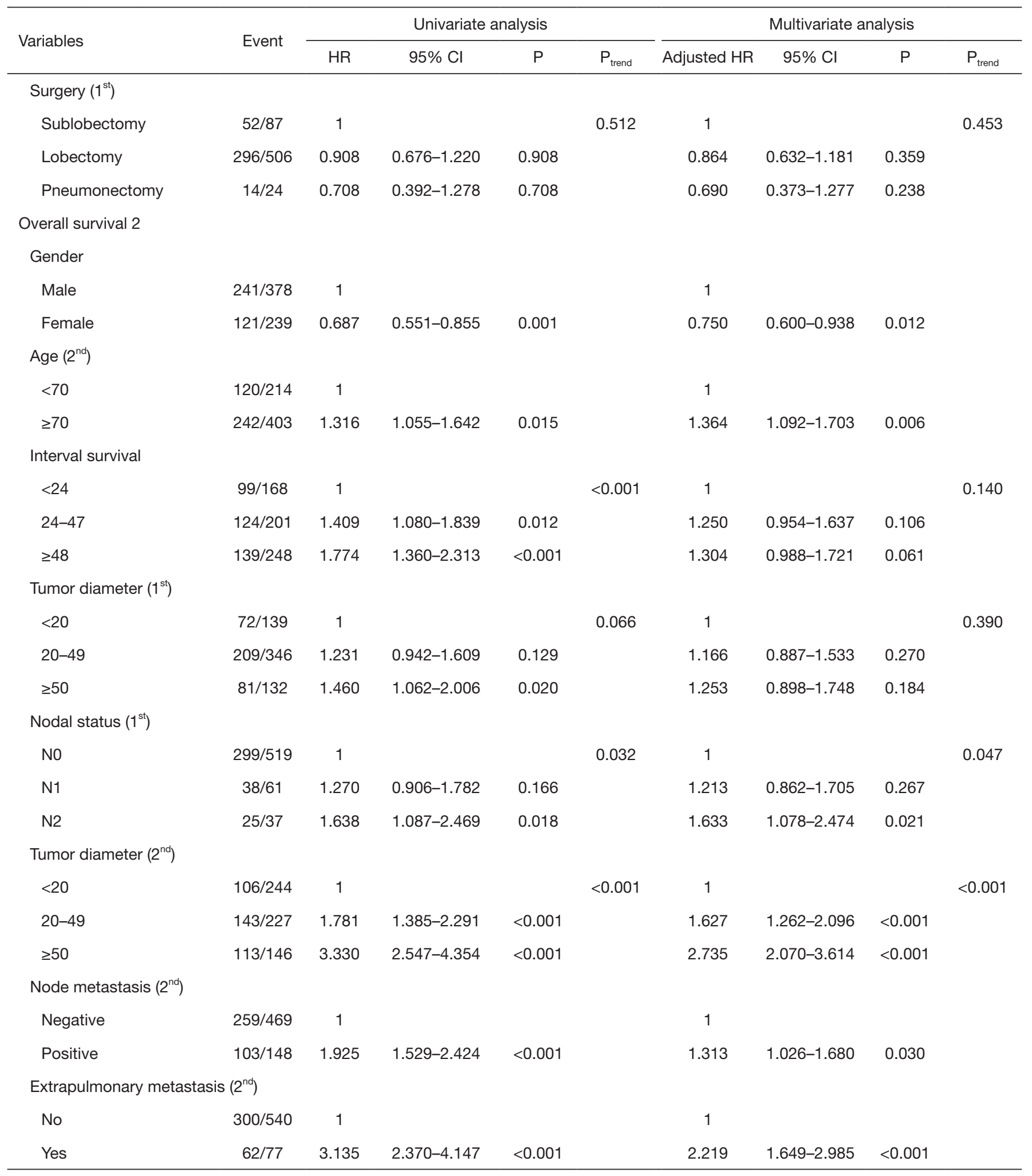

HR, hazard ratio; $95 \% \mathrm{Cl}, 95 \%$ confidence interval. 


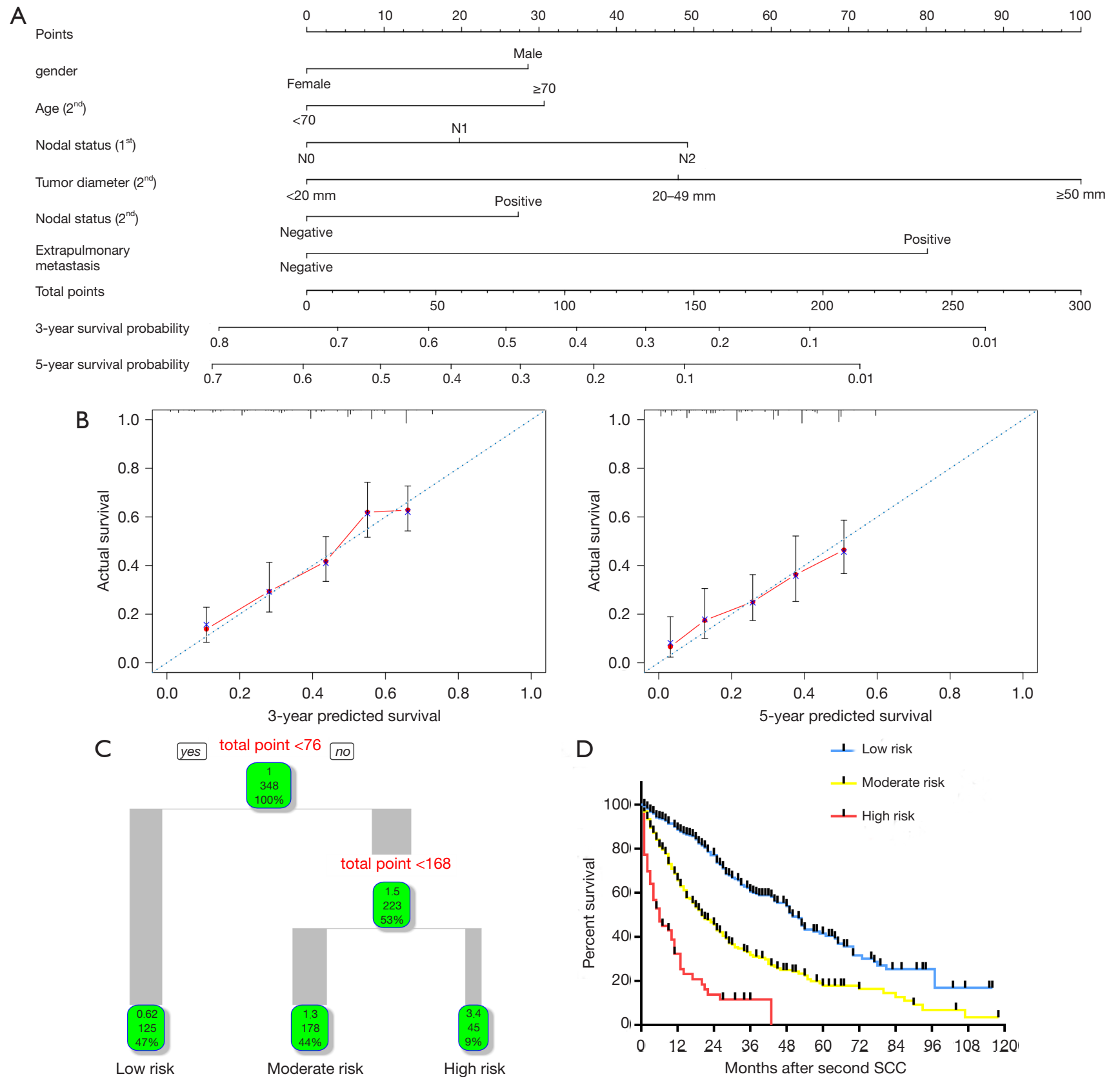

Figure 3 Establishment of a risk stratification system for OS2. (A) Prognostic nomogram for OS2 in patients with metachronous second squamous cell lung cancer; (B) the calibration curves for predicting patient survival at each time point; (C) RPA grouping into three risk categories for OS2; (D) the Kaplan-Meier survival curve for OS2 is well stratified by the RPA risk group. SCC, squamous cell carcinoma; OS, overall survival; RPA, recursive partitioning analysis.

performed RPA for OS2 according to the nomogram score and partitioned the patient population into three risk strata defined as follows: low risk (nomogram score $<76)(\mathrm{n}=285$, $55.8 \%$ ), moderate risk (nomogram score $\geq 76 \&<168$ ) $(\mathrm{n}=276,31.9 \%)$, and high risk (nomogram score $>168)$ $(\mathrm{n}=56,14.3 \%)$ (Figure 3C). The risk stratification system presents good operating characteristics for the stratification of OS2. The median survival after msPSC for the lowrisk, moderate-risk, and high-risk groups was 50, 20, and 5 months, respectively $(\mathrm{P}<0.001)$ (Figure 3D). 

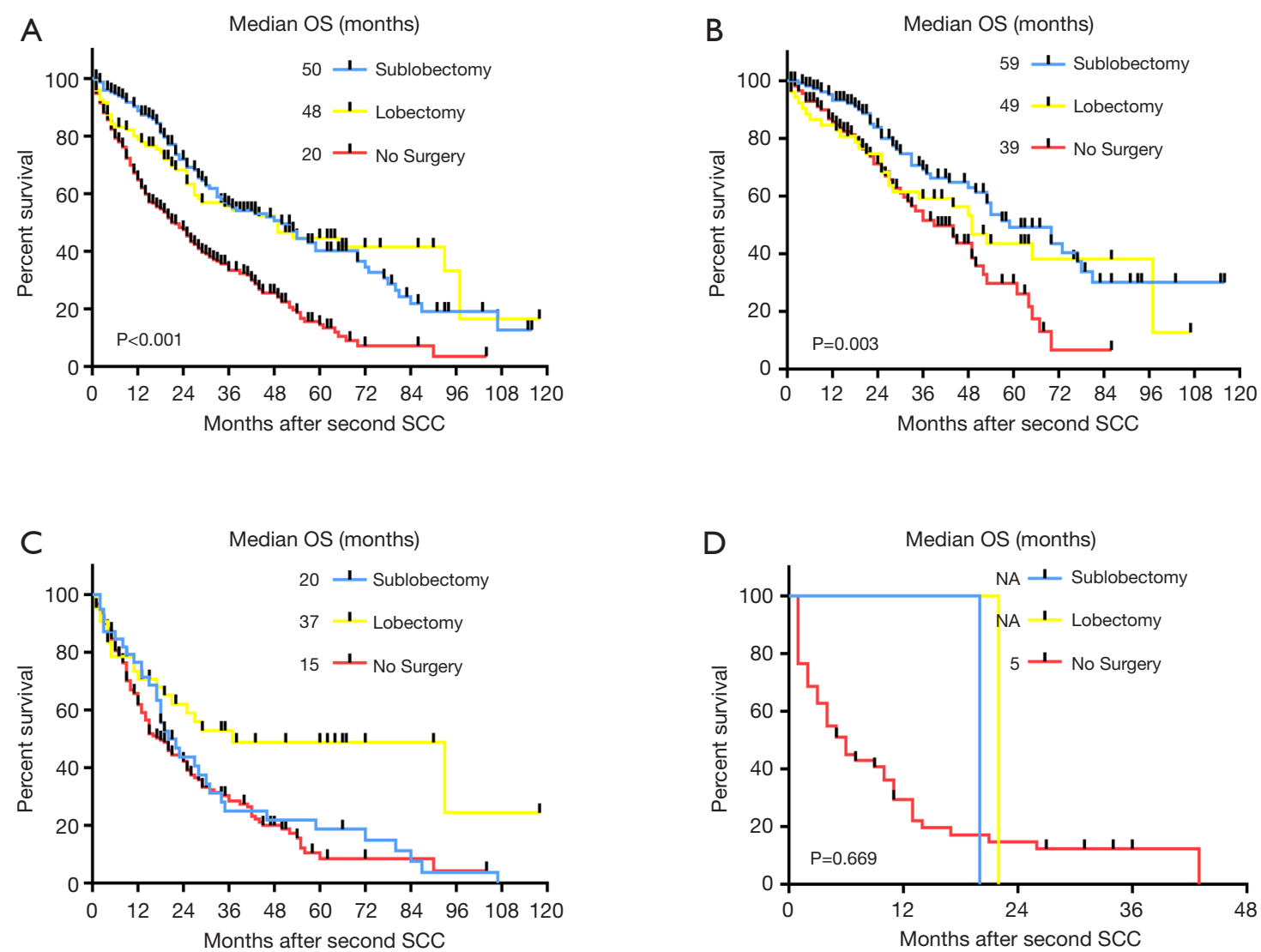

Figure 4 Association between treatment and prognosis in patients with different risk stratification. The impact of surgery type on OS2 for the entire cohort (A), low-risk group (B), moderate-risk group (C), and high-risk group (D). OS, overall survival; SCC, squamous cell carcinoma.

\section{Risk stratification, treatment strategy, and OS2}

Patients with msPSC who underwent surgery presented longer OS2 times than those who did not undergo surgery (median, 49 vs. 20 months, $\mathrm{P}<0.001$ ) (Figure 4A). Then, we estimated the association between surgery type and OS2 in patients with different stratifications. For the lowrisk group, the prognosis of sublobectomy was comparable to that of lobectomy (median survival: $59 \mathrm{vs} .49$ months, $\mathrm{P}=0.219$ ) (Figure $4 B$ ). For the moderate-risk group, the prognosis of sublobectomy was inferior to that of lobectomy (median: 37 vs. 20 months, $\mathrm{P}=0.026$ ) (Figure 4C). For the high-risk group, surgery was only performed in two patients (3.6\%) (Figure 4D). The efficacy of chemotherapy was not observed; radiotherapy was associated with better outcomes in patients who did not undergo surgery for msPSC (median survival, 26 vs. 11 months, $\mathrm{P}<0.001$ ) (Figure $\mathrm{S} 1$ ).

\section{Discussion}

Metachronous second lung cancer is a common disease (4-6). However, for metachronous second lung cancer with the same pathology as the first lung cancer, the method to distinguish tumour clonality has not yet been well established, which makes it difficult to determine accurate staging and appropriate therapeutic strategies. In this study, we recruited msPSC patients among survivors of previously resected PSCs from a large, population-based database, constructed a prognostic model, established a risk stratification system, and attempted to identify appropriate treatment strategies for these patients. To the best of our knowledge, this is the first study to address this issue in the literature.

In this study, we defined interval survival as the interval between the first PSC and msPSC and found that it was 
significantly influenced by age and side (Table 2). It could be expected that older patients would encounter a limited interval survival due to the limited life-time. The shorter interval survival among contralateral msPSCs might be partly explained by the process of functional compensation. Metachronous lung cancer is more likely to be located on the contralateral side, since contralateral pulmonary function would account for a larger proportion after the first resection. This speculation is supported by Yang et al., who observed most $(80.2 \%)$ metachronous lung cancer in the contralateral lobe after first resection (16).

In the literature, interval survival has long been regarded as an important indicator for the tumour clonality of metachronous multiple lung cancer. In the first edition of the diagnostic criteria proposed by Martini et al., a time interval $>2$ years is a necessary condition for the diagnosis of metachronous multiple primary lung cancer (mMPLC) (10). This edition was further modified by the ACCP in 2003. According to their suggestions, interval survival $>4$ years is a necessary condition for mMPLC, and interval survival $<2$ years is a necessary condition for metastatic lung cancer (9). This suggestion is still used in the following editions $(7,8)$. In our study, the association between interval survival and OS2 was evaluated as well. According to our results, longer interval survival (interval $<24$ vs. $24-47 v s . \geq 48$ months) leads to longer OS2 (23 vs. 27 vs. 49 months) $(\mathrm{P}<0.001)$. However, this association missed significance after adjusting for other confounders $(\mathrm{P}=0.140)$ (Table 2). A similar result was also reported by Hamaji et al. (11). It has been widely accepted that the characteristics of tumour clonality greatly impact staging information and long-term survival. It is plausible that since interval survival is not an independent prognostic factor for OS2, it should not be an essential factor to distinguish tumour clonality. The criterion for MPLC, especially regarding the issues of interval survival, might be biased and merit further modification.

Following an improvement in the prognosis of patients with lung cancer, we also observed an elevated risk of developing second lung cancer (17). However, until now, it is still difficult to distinguish the tumour clonality and determine the accurate stage for metachronous second lung cancer when its pathology is the same as the first. It is worth noting that this is a common problem in clinics. For example, Hamaji et al. recruited 161 patients with metachronous second lung cancer, and 123 (76.4\%) of them were diagnosed with the same pathology as the first lung cancer (11). Therefore, this study sought to establish a prognostication system for these patients with the aim of resolving the dispute of tumour clonality. To achieve this goal, the characteristics of second lung cancer were recorded, such as tumour diameter, node metastasis (negative $v s$. positive), and extrapulmonary metastasis. Finally, in addition to these parameters, age $\left(2^{\text {nd }}\right)$, gender, and nodal status $\left(1^{\text {st }}\right)$ were included in the nomogram. Because nodal status $\left(1^{\text {st }}\right)$ has an independent impact on OS2, we propose to view metachronous second lung cancer from a continuous perspective.

It has been widely accepted that surgery is an effective treatment for operable metachronous lung cancer $(11,16)$. Similarly, in this study, surgery was associated with a better OS2 than no surgery (median, 49 vs. 20 months, $\mathrm{P}<0.001$ ). After risk stratification, the prognosis of sublobectomy was comparable to that of lobectomy in the low-risk group (median, 59 vs. 49 months, $\mathrm{P}=0.219$ ) but inferior to that of lobectomy in the moderate-risk group (median, $20 \mathrm{vs}$. 37 months, $\mathrm{P}=0.026$ ). Risk stratification seems to facilitate clinical treatment decisions. In addition, for patients with msPSC who did not undergo surgery, radiotherapy was associated with improved survival (median survival, $26 \mathrm{vs}$. 11 months, $\mathrm{P}<0.001)$. Aggressive local therapy is warranted for msPSC.

Our study has several limitations. First, because of the nature of the SEER data, some well-known prognostic factors, such as cigarette smoking and tumour markers, were not included. However, the calibration plots presented good agreement between the nomogram predictions and actual observations, and the c-index was 0.678 . These results indicate that the findings are informative regarding patient outcomes. Second, the efficacy of chemotherapy could have been underestimated due to the ambiguous record (yes vs. no/unclear) and unaware regimen in the SEER 18 Custom Database. Third, although we carried out 1,000 bootstrap resamples for interval validation, the results still need further external validation with other populations. Fourth, the problem of tumour clonality was not solved by our study. Therefore, we could not quantify the efficacy of the risk stratification by comparison with the current TNM staging system, although prognosis was stratified fairly well according to the survival curves. Fifth, because the biological behaviour of lung adenocarcinoma is significantly different from that of PSC, especially in recurrence/ metastatic patterns and multiple nodule models, we did not include patients with metachronous adenocarcinoma lung cancer with previously resected adenocarcinoma in this study (18-20). Therefore, our results, including the 
prognostic model, risk stratification system, and treatment recommendations, are not suitable for patients with metachronous adenocarcinoma.

In conclusion, the RPA-based clinical nomogram appears to be suitable for the prognostic prediction and risk stratification of msPSC patients with previously resected PSC. This model validates and refines the classification rules previously used by other authors; it is based on variables that are easy to obtain, it is easy to use and has potential implications for clinical management and study design.

\section{Acknowledgments}

Funding: This work was supported by grants from the Guangzhou Health Science and Technology Project (20211A010001).

\section{Footnote}

Reporting Checklist: The authors have completed the STROBE reporting checklist. Available at https://jtd. amegroups.com/article/view/10.21037/jtd-21-1164/rc

Peer Review File: Available at https://jtd.amegroups.com/ article/view/10.21037/jtd-21-1164/prf

Conflicts of Interests: All authors have completed the ICMJE uniform disclosure form (available at https://jtd.amegroups. com/article/view/10.21037/jtd-21-1164/coif). The authors have no conflicts of interest to declare.

Ethical Statement: The authors are accountable for all aspects of the work in ensuring that questions related to the accuracy or integrity of any part of the work are appropriately investigated and resolved. The study was conducted in accordance with the Declaration of Helsinki (as revised in 2013). The study was approved by institutional ethics board of Guangzhou First People's Hospital (K2020-066-01) and individual consent for this retrospective analysis was waived.

Open Access Statement: This is an Open Access article distributed in accordance with the Creative Commons Attribution-NonCommercial-NoDerivs 4.0 International License (CC BY-NC-ND 4.0), which permits the noncommercial replication and distribution of the article with the strict proviso that no changes or edits are made and the original work is properly cited (including links to both the formal publication through the relevant DOI and the license). See: https://creativecommons.org/ licenses/by-nc-nd/4.0/.

\section{References}

1. Bray F, Ferlay J, Soerjomataram I, et al. Global cancer statistics 2018: GLOBOCAN estimates of incidence and mortality worldwide for 36 cancers in 185 countries. CA Cancer J Clin 2018;68:394-424.

2. Henley SJ, Richards TB, Underwood JM, et al. Lung cancer incidence trends among men and women--United States, 2005-2009. MMWR Morb Mortal Wkly Rep 2014;63:1-5.

3. Morgensztern D, Waqar S, Subramanian J, et al. Improving survival for stage IV non-small cell lung cancer: a surveillance, epidemiology, and end results survey from 1990 to 2005. J Thorac Oncol 2009;4:1524-9.

4. Ripley RT, McMillan RR, Sima CS, et al. Second primary lung cancers: smokers versus nonsmokers after resection of stage I lung adenocarcinoma. Ann Thorac Surg 2014;98:968-74.

5. Lou F, Huang J, Sima CS, et al. Patterns of recurrence and second primary lung cancer in early-stage lung cancer survivors followed with routine computed tomography surveillance. J Thorac Cardiovasc Surg 2013;145:75-81; discussion 81-2.

6. Johnson BE. Second lung cancers in patients after treatment for an initial lung cancer. J Natl Cancer Inst 1998;90:1335-45.

7. Kozower BD, Larner JM, Detterbeck FC, et al. Special treatment issues in non-small cell lung cancer: Diagnosis and management of lung cancer, 3rd ed: American College of Chest Physicians evidence-based clinical practice guidelines. Chest 2013;143:e369S-99S.

8. Shen KR, Meyers BF, Larner JM, et al. Special treatment issues in lung cancer: ACCP evidencebased clinical practice guidelines (2nd edition). Chest 2007;132:290S-305S.

9. Detterbeck FC, Jones DR, Kernstine KH, et al. Lung cancer. Special treatment issues. Chest 2003;123:244S-58S

10. Martini N, Melamed MR. Multiple primary lung cancers. J Thorac Cardiovasc Surg 1975;70:606-12.

11. Hamaji M, Allen MS, Cassivi SD, et al. Surgical treatment of metachronous second primary lung cancer after complete resection of non-small cell lung cancer. J Thorac Cardiovasc Surg 2013;145:683-90; discussion 690-1.

12. Detterbeck FC, Marom EM, Arenberg DA, et al. The 
IASLC Lung Cancer Staging Project: Background Data and Proposals for the Application of TNM Staging Rules to Lung Cancer Presenting as Multiple Nodules with Ground Glass or Lepidic Features or a Pneumonic Type of Involvement in the Forthcoming Eighth Edition of the TNM Classification. J Thorac Oncol 2016;11:666-80.

13. Loukeri AA, Kampolis CF, Ntokou A, et al. Metachronous and synchronous primary lung cancers: diagnostic aspects, surgical treatment, and prognosis. Clin Lung Cancer 2015;16:15-23.

14. Zheng Y, Fu S, He T, et al. Predicting prognosis in resected esophageal squamous cell carcinoma using a clinical nomogram and recursive partitioning analysis. Eur J Surg Oncol 2018;44:1199-204.

15. Team RC. R: A Language and Environment for Statistical Computing: Version 3.4.1. 2017.

16. Yang X, Zhan C, Li M, et al. Lobectomy Versus Sublobectomy in Metachronous Second Primary Lung

Cite this article as: Fu SS, Zheng YZ, Qin XY, Yang XP, Shen P, Cai WJ, Li XQ, Liao HY. Establishing a prognostic model for metachronous second squamous cell lung cancer in patients with resected squamous cell lung cancer. J Thorac Dis 2022;14(1):90-101. doi: 10.21037/jtd-21-1164
Cancer: A Propensity Score Study. Ann Thorac Surg 2018;106:880-7.

17. Surapaneni R, Singh P, Rajagopalan K, et al. Stage I lung cancer survivorship: risk of second malignancies and need for individualized care plan. J Thorac Oncol 2012;7:1252-6.

18. Ashley DJ, Davies HD. Cancer of the lung. Histology and biological behavior. Cancer 1967;20:165-74.

19. Schuurbiers OC, Meijer TW, Kaanders JH, et al. Glucose metabolism in NSCLC is histology-specific and diverges the prognostic potential of 18FDG-PET for adenocarcinoma and squamous cell carcinoma. J Thorac Oncol 2014;9:1485-93.

20. Meijer TW, Schuurbiers OC, Kaanders JH, et al. Differences in metabolism between adeno- and squamous cell non-small cell lung carcinomas: spatial distribution and prognostic value of GLUT1 and MCT4. Lung Cancer 2012;76:316-23. 
Supplementary

Table S1 Computational formula of nomogram score for each prognostic factor

\begin{tabular}{ll}
\hline & Computational formula of nomogram score \\
\hline Gender & Male $=28.6 ;$ Female $=0$ \\
Age (2nd) & $<70=0 ; \geq 70=30.7$ \\
Nodal status (1st) & $\mathrm{NO}=0 ; \mathrm{N} 1=19.7 ; \mathrm{N} 2=49.2$ \\
Tumor diameter (2nd) & $<20 \mathrm{~mm}=0 ; 20-49 \mathrm{~mm}=48.0 ; \geq 50 \mathrm{~mm}=100.0$ \\
Nodal status (2nd) & Negative $=0 ;$ Positive $=27.3$ \\
Extrapulmonary metastasis (2nd) & Negative $=0 ;$ Positive $=80.2$ \\
\hline
\end{tabular}



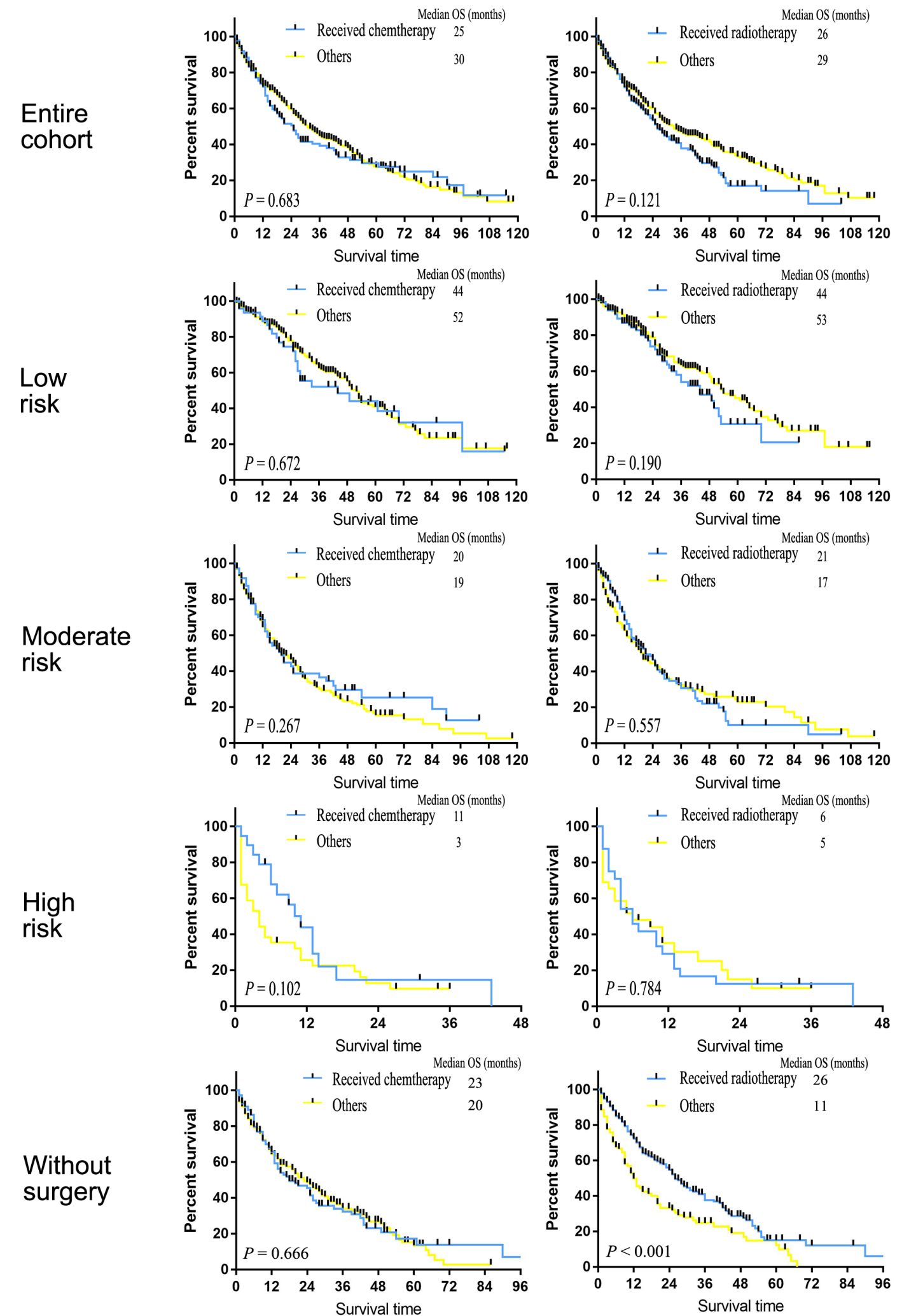

Figure S1 The impact of radiotherapy and chemotherapy on OS2 for the entire cohort, low-risk group, moderate-risk group, high-risk group, and no-surgery group. 